\title{
Graphene-Oxide and Hydrogel Coated FBG-Based pH Sensor for Biomedical Applications ${ }^{+}$
}

\author{
Leonardo Binetti *, Alicja Stankiewicz and Lourdes S. M. Alwis \\ School of Engineering and the Built Environment, Edinburgh Napier University, Edinburgh EH10 5DT, UK; \\ a.stankiewicz@napier.ac.uk (A.S.); 1.alwis@napier.ac.uk (L.S.M.A.) \\ * Correspondence: 1.binetti@napier.ac.uk; Tel.: +44-788-971-0861 \\ † Presented at the Eurosensors 2018 Conference, Graz, Austria, 9-12 September 2018. \\ Published: 3 December 2018
}

\begin{abstract}
A hydrogel coated fibre grating-based $\mathrm{pH}$ sensor for biomedical applications has been realised, where Graphene Oxide (GO) had been used to enhance the bonding between the coating and the fibre. Two methods of deposition of GO were analysed i.e., evaporation and coelectroplating. The paper concludes that the system of GO evaporated on the fibre + the hydrogel has a sensitivity much higher, $(6.1 \pm 0.5) \mathrm{pm} / \mathrm{pH}$, than the system of $\mathrm{Cu}$ and $\mathrm{GO}$ co-electroplated + the hydrogel, $(1.9 \pm 0.1) \mathrm{pm} / \mathrm{pH}$, for a $\mathrm{pH}$ range between 2 to 10 . The other conclusion is that the first system has a less coating bonding energy with the optical fibre whereas the second system has a stronger bonding energy, with better durability.
\end{abstract}

Keywords: graphene oxide; fibre optic; $\mathrm{pH}$; sensing; FBG; roughness; surface functionalisation; wettability; GO; biomedical application

\section{Introduction}

In living organisms, metabolic processes can only take place if specific physical and chemical conditions are met and this is the reason for maintaining the $\mathrm{pH}$ of extracellular fluids, including blood plasma, at 7.4 by efficient buffering systems [1]. The level of $\mathrm{pH}$ in stomach content could lead to the identification of various illnesses, especially in children and thus there had been a growing interest in research on non-invasive and intrinsically safe sensing techniques for $\mathrm{pH}$ measurement. Traditional $\mathrm{pH}$ sensing techniques use acid-based indications and electrodes, while in comparison, fibre optic-based $\mathrm{pH}$ sensors have the advantages of electrical inertness, immunity to electromagnetic interference, and miniature size. This makes them ideal for biomedical applications, especially considering the volume of information and safety aspects. Fibre optic-based $\mathrm{pH}$ sensor techniques are of two-fold: utilization of absorption and fluorescence; coating pH-sensitive material on fibre [2-5].

The concept of in fibre grating devices for $\mathrm{pH}$ sensing includes the fibre grating, i.e., Fibre Bragg Grating (FBG), acting as the basis of the device and the $\mathrm{pH}$ sensing mechanism exploits the strain effect induced on the FBG through the swelling of a $\mathrm{pH}$-sensitive polymer coating applied on the grating region.

Shivananju et al. had proven [6] that hydrogel made by alginic acid sodium salt (2\% in aqueous solution at $20^{\circ} \mathrm{C}, \mathrm{C}_{6} \mathrm{H}_{9} \mathrm{NaO}_{7}$ ) gets a form of viscous hydrocolloid or gels in water by crosslinking with the linker $\mathrm{CaCl}_{2}(0.8 \mathrm{M})$. The crosslinking agent of the divalent cations $\mathrm{Ca}^{2+}$ in the polymeric network form the hydrogel by electrostatic interaction with the carboxyl groups of sodium alginate, which are sensitive to $\mathrm{pH}$ variation. The sodium alginate has been selected because of its minimal invasive properties (biocompatibility and ease of gelation) and for its vast application in biomedical science and engineering [7]. 
Hydrogels offer some limitations when they are coated on substrates due to the low interfacial toughness. For instance, they have a very low level of coefficient of friction of gels $\mu \sim 10^{-3}-10^{-4}[8]$, while bonding a water-rich hydrogel [9]. Some studies used either approaches like functionalising the substrate surface with some nonporous solids either via self-assembled monolayers [10], or using the strong bonding between the hydrogel and elastomers by employing the ultraviolet-initiated polymerisation [11] or adding nanoparticles of silica, acting as connectors between polymer chains [12]. In this work, the friction has been done by increasing the roughness and hence increasing the wettability of the hydrogel on the substrate material (fibre optic) by using graphene oxide.

\section{Materials and Methods}

Graphite with the particle size less than $50 \mu \mathrm{m}$ was chosen to produce and lower the degradation problem of Graphene Oxide [13]. GO was made by applying modifications to the method described by Zaaba et al. [14], synthesized using the Hummers modified method. The FBG was first coated with GO using two different GO deposition techniques (i.e., evaporation and co-electroplating), to increase the wettability of the hydrogel, and re-coated with the polymeric layer containing sodium alginate and calcium chloride. While doing so, the Bragg wavelength was continuously monitored with the interrogator system Micron Optics SM125 and then $24 \mathrm{~h}$ were allowed for the sensor to stabilise in air at room temperature. The applied method is detailed herewithbelow.

\subsection{Coating Procedure}

\subsubsection{Evaporation Deposition Method}

A solution of $1 \mathrm{~g} / \mathrm{L}$ of $\mathrm{GO}(\mathrm{pH} 2.5 \pm 0.1)$ in de-ionised water was prepared and then subjected to an ultrasonic bath for one hour to exfoliate the GO (i.e., in order to avoid conversion to graphite oxide [15]). The FBG sensors were then put onto a petri dish, $1 \mathrm{~mL}$ of GO solution $(1 \mathrm{~g} / \mathrm{L})$ was added on top of the fibre. The oven was set at $90{ }^{\circ} \mathrm{C}$ for $20 \mathrm{~min}$ to allow evaporation of water from the solution. Then the fibre was turned over to the other side and the same coating process was repeated. Due to the evaporation method, at $90^{\circ} \mathrm{C}$, the concentration of GO solution gradually became more concentrated and more attached to the fibre. The sample was analysed using the SEM (Tescan Vega 3 LMU).

\subsubsection{Co-Electroplating Deposition Method}

The technique used involved co-electroplating of $\mathrm{Cu}$ and the GO simultaneously onto the cathode while placing the optical fibre on top of the cathode. The copper plates used were of $(0.50 \pm$ $0.01) \mathrm{mm}$ depth, $(10.00 \pm 0.01) \mathrm{mm}$ width and $(40.00 \pm 0.01) \mathrm{mm}$ length. The GO solution was of $1 \mathrm{~g} / \mathrm{L}$ ( $\mathrm{pH} 2.5 \pm 0.1$ ) and was left in the ultrasonic bath again for one hour before the deposition process begun. The fibre was placed onto the cathode with a potential of $15 \mathrm{~V}$ for $10 \mathrm{~min}$ and a distance between the two electrodes of $2 \mathrm{~cm}$. The fibre was then placed in the oven for $20 \mathrm{~min}$ at $90{ }^{\circ} \mathrm{C}$ and the process was repeated again by turning the fibre over to the other side and analysed using the SEM as discussed earlier.

\subsubsection{Hydrogel Coating}

The hydrogel layer deposition was achieved using a dip-coating mechanism in which the fibre (containing GO coated FBG) was immersed (for $2 \mathrm{~min}$ ) into the solution of sodium alginate and then extracted from the solution at a speed of $5 \mathrm{~mm} / \mathrm{min}$, since the coating was neither uniform nor continuous at higher coating speeds. The fibre was then immersed into the calcium chloride solution for $10 \mathrm{~s}$ and extracted at a speed of $60 \mathrm{~mm} / \mathrm{min}$ (since the hydrogel could contain more $\mathrm{Ca}^{2+}$ if it is immersed for longer period). Before doing the $\mathrm{pH}$ analysis, the two systems were left to dry for $24 \mathrm{~h}$.

\section{Results and Discussion}

Coating of hydrogel on fibre could be challenging due to poor bonding between the polymer and the glass surface, thus increasing the surface area by increasing the roughness of the surface to 
have better wettability. In this study, both processes of deposition of GO had been investigated, followed by the coating of the hydrogel. It could be seen that a non-uniform and non-continuous coating for both the two methods of deposition had been achieved, increasing the surface roughness, as shown in Figure 1. The electrostatic coating given by the evaporation had less bonding strength between the particles and the optic fibre, as shown in Figure 1a. The hydrogel was then applied as discussed in Section 2.1.3.

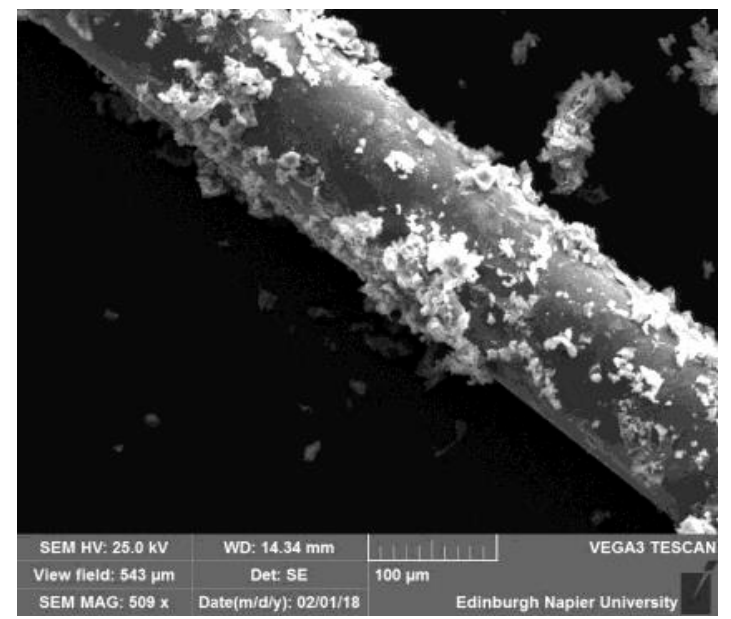

(a)

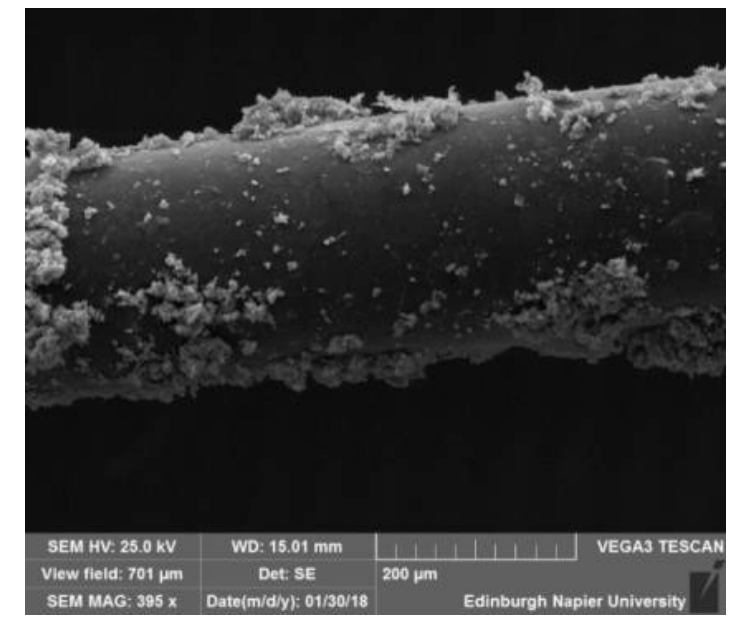

(b)

Figure 1. SEM image of the fibre with (a) GO evaporated; (b) GO co-electroplated.

It should be noted while producing the sensor for biological applications, that hydrogel degrades under different mechanisms depending on $\mathrm{pH}$. When it is subjected to $\mathrm{pH}$ above 10.0, it decomposes because of $\beta$-elimination mechanisms. Below $\mathrm{pH} 5.0$ acid-catalysed hydrolysis causes hydrogel degradation [16]. For this reason, the system was immersed for $2 \mathrm{~min}$ in different $\mathrm{pH}$ solutions. There was a correspondence between the variation in $\mathrm{pH}$ and the respective variation in the FBG resonance wavelength for both GO deposition methods at room temperature, as depicted in Figure 2. There was a dramatic difference in sensitivity across the two methods. The evaporated GO with the hydrogel having a sensitivity of $(6.1 \pm 0.5) \mathrm{pm} / \mathrm{pH}$ whereas the co-electrodeposited GO with the hydrogel has a relatively less sensitivity of $(1.9 \pm 0.1) \mathrm{pm} / \mathrm{pH}$. Even though the sensitivity is higher in the first case, the coating was not strongly bonded to the fibre. In the second method, even though with less sensitivity, the overall performance was higher in terms of strong bonding to the optic fibre due to the strongly attached GO particles.

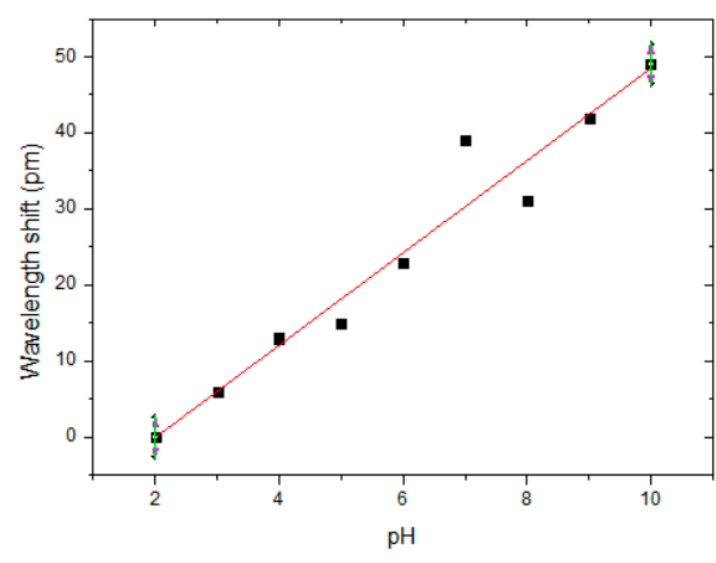

(a)

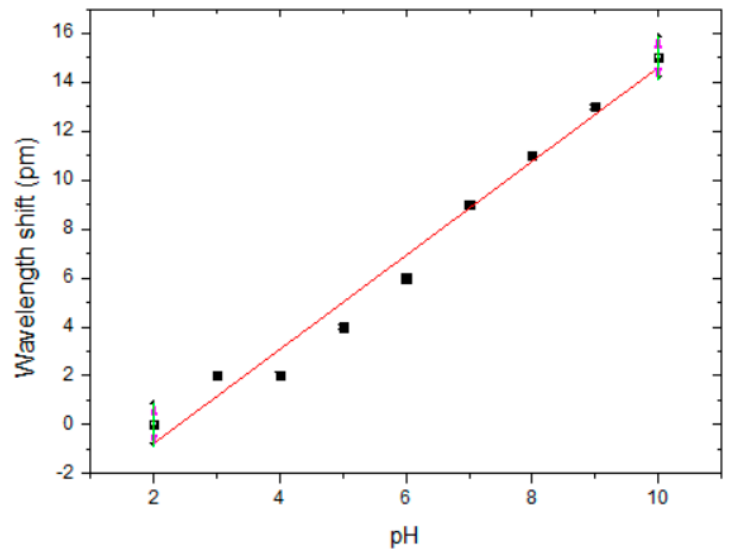

(b)

Figure 2. $\mathrm{pH}$ calibration curve for hydrogel coating on fibre sensors with (a) GO evaporated; (b) GO co- electroplated, techniques. 


\section{Conclusions}

A uniform coating of hydrogel across the sensing element was achieved through the increase of the surface roughness on the optical fibre. The two methods exhibited advantages and disadvantages. The GO evaporated + hydrogel had higher sensitivity $(6.1 \pm 0.5) \mathrm{pm} / \mathrm{pH}$ than the GO co-electroplated + hydrogel, $(1.9 \pm 0.1) \mathrm{pm} / \mathrm{pH}$. However, at the same time, the first system was easily removed, whereas the other one was strongly attached to the optic fibre due to the strong bonding between GO and the metallic copper to the silica.

\section{References}

1. Salvo, P.; Calisi, N.; Melai, B.; Cortigiani, B.; Mannini, M.; Caneschi, A.; Lorenzetti, G.; Paoletti, C.; Lomonaco, T.; Paolicchi, A.; et al. Temperature and $\mathrm{pH}$ sensors based on graphenic materials. Biosens. Bioelectron. 2017, 91, 870-877.

2. Jeon, D.; Yoo, W.J.; Seo, J.K.; Shin, S.H.; Han, Ki.; Kim, S.G.; Park, J.Y.; Lee, B. Fibre-optic pH sensor based on sol-gel film immobilized with neutral red. Opt. Rev. 2013, 20, 209-213.

3. Aldaba, A.L.; González-Vila, Á.; Debliquy, M.; Lopez-Amo, M.; Caucheteur, C.; Lahem, D. Polyanilinecoated tilted fibre Bragg gratings for $\mathrm{pH}$ sensing. Sens. Actuators 2018, 254, 1087-1093.

4. Gu, B.; Yin, M.; Zhang, A.P.; Qian, J.; He, S. Biocompatible fibre-optic pH sensor based on optical fibre modal interferometer self- assembled with sodium alginate/polyethylenimine coating. IEEE Sens. 2012, 12, 1477-1482.

5. Zhao, Y.; Lei, M.; Liu, S.X.; Zhang, Q. Smart hydrogel-based optical fibre SPR sensor for pH measurements. Sens. Actuators B Chem. 2018, 261, 226-232.

6. Shivananju, B.; Priydarshi, M.K.; Mahapatra, D.R.; Hegde, G.M.; Asokan, S. pH Sensing by Single and Multi-Layer Hydrogel Coated Fibre Bragg Grating. In Proceedings of the 2012 1st International Symposium on Physics and Technology of Sensors (ISPTS-1), Pune, India, 7-10 March 2012.

7. Mooney, D.J.; Yong, Lee, K.Y. Alginate: Properties and biomedical applications. Prog. Polym. Sci. 2012, 37, 106-126, doi:10.1016/j.progpolymsci.2011.06.003.

8. Gong, J.P. Friction and lubrication of hydrogels-Its richness and complexity. Soft Matter 2006, 2, 75447552.

9. Tang, J.; Li, J.; Vlassak, J.J.; Suo, Z. Adhesion between highly stretchable materials. Soft Matter 2016, 12, 1093-1099.

10. Yuk, H.; Zhang, T.; Lin, S.; Alberto Parada, G.; Zhao, X. Tough bonding of hydrogels to diverse non-porous surfaces. Nat. Mater. 2015, 15, 190-196.

11. Yuk, H.; Zhang, T.; Lin, S.; Alberto Parada, G.; Zhao, X. Skin-inspired hydrogel-elastomer hybrids with robust interfaces and functional microstructures. Nat. Commun. 2016, 7, 12028.

12. Rose, S.; Prevoteau, A.; Paul, E.; Hourdet, D.; Marcellan, A.; Leibler, L. Nanoparticles solutions as adhesives for gels and biological tissues. Nature 2014, 505, 382-385.

13. Gao, W. Synthesis, Structure, and Characterizations. In Graphene Oxide: Reduction Recipes, Spectroscopy, and Applications; Springer: Cham, Germany, 2015; pp.1-28.

14. Zaaba, N.; Foo, K.; Hashim, U.; Tan, S.J; Liu, W.W.; Voon, C.H. Synthesis of Graphene Oxide using Modified Hummers Method: Solvent Influence. Procedia Eng. 2017, 184, 469-477.

15. Mahmood, H.; Tripathi, M. Enhancement of interfacial adhesion in glass fibre/epoxy composites by electrophoretic deposition of graphene oxide on glass fibres. Compos. Sci. Technol. 2016, 126, 149-157.

16. Pawar, S.N.; Edgar, K.J. Alginate derivatization: A review of chemistry, properties and applications. Biomaterials 2012, 33, 3279-3305.

(C) 2018 by the authors. Licensee MDPI, Basel, Switzerland. This article is an open access article distributed under the terms and conditions of the Creative Commons Attribution (CC BY) license (http://creativecommons.org/licenses/by/4.0/). 